\title{
Entre malas e viagens: a arte contemporânea e as possibilidades da docência com e para as crianças
}

\section{Between bags and travels: contemporany art and the possibilities of teaching with and for children}

\section{Entre bolsos y viajes: el arte contemporáneo y las posibilidades de enseñar com y para los niños}

Elen Maisa Alves da Silva' https://orcid.org/0000-0002-9898-134X

CUNHA, Susana Rangel Vieira da; CARVALHO, Rodrigo Saballa de. (Orgs.). Arte contemporânea e Educação Infantil: crianças observando, descobrindo e criando. Porto Alegre: Mediação, 2017.

Um mar de histórias, afetos, escolhas, olhares e defesas sobre as infâncias e suas relações e aproximações com a arte é o que constitui Arte Contemporânea e Educação Infantil: crianças observando, descobrindo e criando, obra organizada por Susana Rangel Vieira da Cunha e Rodrigo Saballa de Carvalho e publicada pela Editora Mediação em 2017. Uma bagagem de docências, que reúne a escrita colaborativa de diferentes autores, convida o leitor a "discutir as possibilidades e os limites da escola como o lugar de infância, nos nossos tempos" (QUINTEIRO, 2009, p. 20, grifo do autor), problematizando a educação infantil e as vivências das crianças com a arte contemporânea.

Para além da arte enquanto aula expositiva ou promotora de técnicas e/ou habilidades manuais, nove narrativas docentes evocam a escola infantil e suas aproximações com a arte contemporânea na perspectiva de um contexto cultural e de vida coletiva das infâncias. Neste sentido, ressaltam a arte como experiência (DEWEY, 2010); isto é, um momento singular de investigação e participação da criança em práticas escolares que mobilizam suas vivências, sentidos e conhecimentos.

\footnotetext{
'Mestra em Educação (UFRGS), Professora de Educação Infantil na Prefeitura de Canoas. E-mail: elenmaisa@gmail.com

Olhar de professor, Ponta Grossa, v. 24, p. I-7, e-1757I.022, 2021.

Disponível em <https://revistas2.uepg.br/index.php/olhardeprofessor>
} 
Entre malas e viagens: a arte contemporânea e as possibilidades da docência com e para as crianças

Ao encontro de uma docência inventiva, Suzana Rangel Vieira da Cunha, no capítulo inicial, discorre sobre "Uma arte do nosso tempo para as crianças de hoje", ao colocar em xeque as concepções do professor sobre arte e infância e as implicações no trabalho pedagógico. A autora argumenta que as concepções de arte são culturais, ou seja, construídas em realidades sociais que sustentam artefatos que "produzem nossos modos de planejar e desenvolver propostas nos contextos educacionais" (CUNHA et al., 20I7, p. 9). Por outro lado, ressalta a arte contemporânea enquanto tempo presente e lugar de contestação de paradigmas ao instigar a criança a pensar sobre o mundo da vida e as interações sociais. Neste sentido, o segundo capítulo, Arte, infância, formação docente e cultura na Escola, de Rosa lavelberg, aposta no potencial criativo da criança à medida que a ação docente proporciona "viver a arte na escola de modo autoral" (IAVELBERG, 2017, p. 27). Aponta o compromisso ético, o olhar e a escuta docente como imperativos nos percursos de experimentação e criação de significados e aprendizagens da criança.

Os diferentes modos da escola em aproximar as crianças de artefatos, imagens e/ou narrativas culturais é a discussão de $A$ potência edu(vo)cativa das artes visuais, de Lutiere Dalla Valle e Jéssica Maria Freisleben, terceiro capítulo da obra. Sob o viés da cultura visual, os autores debatem sobre a ação docente que produz experiência educativa e, neste processo, como cada um "atribui sentido e/ou significado a determinados aspectos da vida" (VALLE; FREISLEBEN, 20I7, p. 48). Para tanto, analisam a experiência compartilhada entre professores em formação inicial na licenciatura em Artes Visuais e um coletivo de professoras de turmas do Ensino Fundamental. A vivência da criança em projetos escolares de artes visuais é o proposto por Maria Eduarda Rangel Vieira da Cunha em Visitando e criando a partir de uma exposição de arte contemporânea, quarto capítulo. Através da exploração de materiais inusitados, desafia o imaginário e a criatividade infantil a partir da apreciação de obras de artistas brasileiros da contemporaneidade. Ao longo de escrita, aborda as relações entre afeto, criança, sensibilidade e arte nas ações educacionais.

"A escola é um espaço de arte contemporânea?" é a questão norteadora de Camila Bettim Borges (2017, p. 66) para instigar sobre o lugar da arte na educação. Neste quinto capítulo, Respingos, colagens, vozes, sensações..., as ideias da autora ressaltam a "aproximação entre a infância e a arte contemporânea" (BORGES, 2017, p. 69) em uma reflexão crítica sobre as ações e as experiências das crianças. O desenho como uma linguagem que "comunica, expressa e conta histórias" (BERTASI; CARVALHO, 2017, p. 75) é a defesa de Andressa Thaís Favero Bertasi e Rodrigo Saballa de Carvalho no sexto capítulo, denominado As produções gráfico-plásticas das crianças. Apoiados em Gobbi (2009, 2010) e calcados em outros autores, problematizam a naturalização do desenho, incentivando a pensarmos os traços e marcações infantis como um discurso que apresenta as ideias das crianças sobre a realidade social e cultural em que está imbricada (BERTASI; CARVALHO, 20I7, p. 77-80). O desenho

Olhar de professor, Ponta Grossa, v. 24, p. I-7, e-1757I.022, 2021.

Disponível em <https://revistas2.uepg.br/index.php/olhardeprofessor> 
como uma experiência educativa que convida a conhecer o universo infantil e as particularidades da expressão plástica das crianças. $O$ desenho como um documento e um artefato cultural que expressa o olhar do desenhista sob a vida e suas relações e sinaliza como é "ser criança" em determinado contexto sociocultural. Com a "voz forte" (GOBBI, 2017, p. 89) que propaga a visibilidade de si e dos outros chega a nós através do sétimo capítulo, Crianças, Fotografias, Derivas, redigido por Maria Aparecida Gobbi. No texto, a autora relata a experiência de crianças com fotografias, especialmente, uma pesquisa sobre o uso da máquina fotográfica e as relações das imagens captadas com os cotidianos e experiências das crianças. A autora destaca a percepção docente durante a investigação imagética e apresenta os verbos "olhar, ver, receber e guardar" (GOBBI, 2017, p. 99-100) como possibilidade para conhecer e compor narrativas sobre as pessoas e as relações do cotidiano; ao passo que os verbos "dar, receber e retornar" (GOBBI, 2017, p. I0I) observa a relação entre a imagem e aquele que a aprecia.

O projeto "PesquisAÇÕES" realizado na Universidade Federal do Rio Grande do Sul, é o cenário de investigação de Cayenne Ruschel da Silveira e Stéfani Vieira em Criando com pedaços de papel. Neste oitavo capítulo, advogam que o manuseio de materiais expressivos e diferentes suportes aproximam a criança da arte contemporânea e a impulsiona na criação de novos olhares sobre o mundo (SILVEIRA; VIEIRA, 2017). Especialmente, as autoras referem a potencialidade da expressão infantil através de produções gráfico-plásticas com papéis picados; ações pedagógicas voltadas com vistas à invenção e a composição de imagens que dialogam com as realidades das crianças. $O$ último capítulo, A experiência dos bebês om a arte, de Silvia Pillotto e Carla Clauber, tensiona a arte nos espaços escolares planejados para os bebês e como as ações pedagógicas os posicionam como sujeitos participantes destas vivências. A sensibilidade é apontada pelas autoras como possibilidades de uma docência que instiga os "territórios de experiências e de sentidos" (PILLOTTO; CLAUBER, 20 I7, p. II3) dos bebês, provocando não somente os afetos, mas as relações e aprendizagens.

Este conjunto de vozes docentes ecoaram incertezas e inquietações sobre as práticas artísticas contemporâneas na educação infantil: como pensar (e trabalhar) arte (e que arte) na escola? As escritas ressaltaram uma arte que deve ser presente ao tempo da criança, indagando os clássicos canônicos e os efeitos e sentidos do cotidiano infantil nas propostas pedagógicas. Nas palavras de Larrosa (2019, p. 5), "a experiência, e não a verdade, é o que dá sentido à escritura”. Isso significa uma ação docente que acolhe a prática em arte como uma provocação, ou seja, oferece uma cena pedagógica que incita o entendimento do mundo e contrapõe os estereótipos de forma crítica e sensível.

Ao propor a reflexão sobre as memórias guardadas (e transportadas) na bagagem docente, Cunha e Carvalho (2017) mobilizam a confrontar a agência docente e suas intenções e investimento pedagógico na singularidade da criança em suas produções. Neste sentido, destaco um feixe de 
Entre malas e viagens: a arte contemporânea e as possibilidades da docência com e para as crianças

questões apresentadas pelos diferentes partícipes do livro ao abordarem a problematização sobre o ensino da arte contemporânea:

a) A educação e infância e os seus contextos de inscrição, entendendo a cultura como uma cadeia de instituições e práticas que constroem efeitos e significados sobre as infâncias e definem o pensamento pedagógico sobre o ensino de arte. Ao professor, cabe observar a conjuntura social e as políticas educacionais vigentes e oportunizar práticas capazes de desconstruir padrões e promover o universo da expressão infantil (CUNHA et al., 2017). A escola infantil como um laboratório de pensamentos onde "as crianças de fato fazem arte ao bagunçarem o mundo imagético das formas convencionais" (CUNHA et al., 2017, p. 13).

b) A escola como um lugar de vivências infantis que são investigadas em práticas artísticas que dialogam com o tempo presente da criança. Na perspectiva de uma pedagogia da infância, a criança "toma parte em" e "faz com" (BROUGÈRE; ULMANN, 2012, p. 308) nas ações pedagógicas do professor. Isto significa que a participação ativa da criança e seus processos de imaginação, criação e expressão infantis demandam o envolvimento e partilha de um cotidiano que é coletivo.

c) A organização dos espaços e as diferentes materialidades como provocadores de um corpo infantil que participa de uma experiência em arte que é educativa ao explorar e descobrir o próprio cotidiano. A experimentação espacial e o manuseio de materiais inusitados são potentes em desencadear momentos de estesia na criança à medida que "bagunçam o mundo natural por meio de diferentes modalidades que abarcam as artes visuais" (CUNHA et al., 2017, p. I3). Sob este viés, "valorizar o ambiente como espaço de relações"; isto é, de brincadeiras, descobertas e interações é investir na competência e curiosidade das crianças (HORN, 20I7, p. 27), além de promover diferentes linguagens expressivas (CUNHA et al, 20I7).

d) $O$ cotidiano como fio condutor do currículo na escola infantil, ao entender que a qualidade reside "para além do discurso, na construção do significado" (DAHLBERG; MOSS; PENCE, 2019, p. 119) e o conhecimento surge da simplicidade de um cotidiano que é problematizado. Acolher a criança é pensar o mundo da vida dentro da escola como um "método de trabalho complexo, um modo de ser do adulto, uma ideia chave no processo educativo" (STACCIOLI, 20I3, p. 25). A abordagem educativa é intencional e ao encontro dos campos de experiência das crianças: são as vivências infantis que devem reger os pensamentos e ações da docência como um laboratório dinâmico e contínuo de aprendizagens. Na escola infantil, o currículo é vívido quando se desvia do assistencialismo e da escolarização e o adulto-professor se dispõe a olhar e ouvir os modos de ser, de aprender e de conhecer das crianças (SILVA; CARVALHO, 2020).

e) A figura da docência na educação infantil, refletida nos aspectos organizacionais e/ou dinâmicos da própria profissão; o trabalho do modo como é vivenciado e significado por ele e para ele. As práticas

Olhar de professor, Ponta Grossa, v. 24, p. I-7, e-1757I.022, 2021.

Disponível em <https://revistas2.uepg.br/index.php/olhardeprofessor> 
pedagógicas percebidas como uma "atividade humana interativa em que a interação entre as crianças e o objeto de trabalho são, portanto, um aspecto fundamental na composição dos modos de ser docente" (CARVALHO; GUIZZO, 2020, p. 7). A didática como um conjunto de práticas que "concebe a criança como sujeito histórico e de direitos, detentora e promotora de culturas, que são partilhadas com o professor e as outras crianças a partir de uma escuta atenta" (SILVA; CARVALHO, 2020, p. 499).

Pensar a arte contemporânea e as aproximações com as infâncias foi a convocatória da obra organizada por Cunha e Carvalho (2017). A cada capítulo, um coletivo de ideias tensionou sobre o propósito de práticas artísticas percebendo-as para além de ações docentes estáticas e ao encontro de uma criança que "tem de aprender de maneiras diversificadas, ricas e profundamente significativas, usando muitas linguagens" (GANDINI et al, 20I9, p. 4). O tempo presente do cotidiano das crianças em experiências educativas "extraordinárias", enriquecidas, que ampliam o repertório infantil e promovem educação social e cidadania ativa.

O professor é o personagem que cria e organiza as situações escolares e não se posiciona somente no lugar do adulto. É aquele que defende a riqueza da interação entre as crianças e tem o desafio de "burilar o olhar" para as experiências artísticas na escola, pensando sobre o potencial inventivo das crianças e o quanto há de marcas culturais em suas produções. A arte na escola como experiência e exploração de linguagens infantis (CUNHA; CARVALHO, 2017) que se expressam como um pensamento visual que é narrado e (re)significado à medida que existe e fala de algo ou alguém e reinventa a história de um cotidiano que é vivido.

Encerro essa viagem de sonhos e desafios docentes que, aqui relatados, animam a um contexto educativo mais alegre e comprometido com as intencionalidades e condições pedagógicas em que ocorrem o processo de criação artística na escola infantil: espaços, vivências, materialidades, tempos e relações. Levo comigo uma nova bagagem, ainda com as incertezas de uma profissão inacabada, porém rica em possibilidades de ser, ouvir, sentir, propor e aprender sobre a arte contemporânea na educação infantil.

\section{Referências}

BERTASI, A. T. F.; CARVALHO, R. S. de. As produções gráfico-plásticas das crianças. In: CUNHA, S. R. V. da; CARVALHO, R. S. de. (Orgs.). Arte contemporânea e educação infantil: crianças observando, descobrindo e criando. Porto Alegre: Mediação, 2017.

BORGES, C. B. Respingos, colagens, vozes, sensações. In: CUNHA, S. R. V. da; CARVALHO, R. S. de. (Orgs.). Arte contemporânea e educação infantil: crianças observando, descobrindo e criando. Porto Alegre: Mediação, 2017.

Olhar de professor, Ponta Grossa, v. 24, p. I-7, e-1757I.022, 2021.

Disponível em <https://revistas2.uepg.br/index.php/olhardeprofessor> 
Entre malas e viagens: a arte contemporânea e as possibilidades da docência com e para as crianças

BROUGÈRE, G. Uma teoria da aprendizagem adaptada: a aprendizagem como participação. In: BROUGÈRE, G.; ULMANN, A. Aprender pela vida cotidiana. Campinas: Autores Associados, 2012.

CARVALHO, R. S. de; GUIZZO, B. S. Cartas de Pasantes como Textos Pedagógicos: momentos de la docencia em educación infantil. Hachetetepé. Revista Científica de Educación y Comunicación. [s.I.], n. 20, p. 6-16, 2020.

CUNHA, S. R. V. da; CARVALHO, R. S. de. (Orgs.). Arte contemporânea e educação infantil: crianças observando, descobrindo e criando. Porto Alegre: Mediação, 2017.

CUNHA, S. R. V. da et al. As artes no universo infantil. Porto Alegre: Mediação, 2017.

DAHLBERG, G.; MOSS, P.; PENCE, A. Qualidade na educação da primeira infância: perspectivas pós-modernas. Tradução de Magda França Lopes, com revisão técnica de Kátia de Souza Amorim. Porto Alegre: Penso, 2019.

DEWEY, J. Arte como experiência. São Paulo: Martins Fontes, 2010.

GANDINI, L. et al. O papel do ateliê na educação infantil: a inspiração de Reggio Emilia. Porto Alegre: Penso, 2019.

GOBBI, M. A. Desenho infantil e oralidade: instrumentos para pesquisas com crianças pequenas. In: FARIA, A. L. de.; DEMARTINI, Z. B.; PRADO, P. D. (Orgs.). Por uma cultura da infância: metodologias de pesquisa com crianças. Campinas: Autores Associados, 2009. p. 69-92.

GOBBI, M. A. Múltiplas linguagens de meninos e meninas e a educação infantil. In: SEMINÁRIO NACIONAL: CURRÍCULO EM MOVIMENTO, I., 20I0, Belo Horizonte. Anais... Belo Horizonte, 2010. P. I-2I. Disponível em: <http://portal.mec.gov.br/index.php?option=com_docman\&view=download\&alias=6678multiplaslinguagens\&category_slug=setembro-2010-pdf\&ltemid=30192>Acesso em: $10 \mathrm{fev} .202 \mathrm{I}$.

GOBBI, M. A. Crianças, fotografias, derivas. In: CUNHA, S. R. V. da; CARVALHO, R. S. de. (Orgs.). Arte contemporânea e educação infantil: crianças observando, descobrindo e criando. Porto Alegre: Mediação, 2017.

HORN, M. da G. S. Brincar e interagir nos espaços da escola infantil. Porto Alegre: Penso, 2017.

LARROSA, J. Pedagogia profana: danças, piruetas e mascaradas. Belo Horizonte: Autêntica Editora, 2019.

PILLOTTO, S.; CLAUBER, C. A experiência dos bebês com a arte. In: CUNHA, S. R. V. da; CARVALHO, R. S. de. (Orgs.). Arte contemporânea e educação infantil: crianças observando, descobrindo e criando. Porto Alegre: Mediação, 2017.

QUINTEIRO, J. Infância e educação no Brasil: um campo de estudos em construção. In: FARIA, A. L. de; DEMARTINI, Z. B. F.; PRADO, P. D. Por uma cultura da infância: metodologias de pesquisas com crianças. Campinas: Autores Associados, 2009.

SILVA, M. O.; CARVALHO, R. S. de. Concepções sobre currículo na educação infantil: ressonâncias da Pedagogia da infância em narrativas de professoras. Currículo Sem Fronteiras. [s.l.], v. 20, p. 497-5।4, 2020.

Olhar de professor, Ponta Grossa, v. 24, p. I-7, e-1757I.022, 2021.

Disponível em <https://revistas2.uepg.br/index.php/olhardeprofessor> 
SILVEIRA, C. R. da.; VIEIRA, S. Criando com pedaços de papel. In: CUNHA, S. R. V. da; CARVALHO, R. S. de. (Orgs.). Arte contemporânea e educação infantil: crianças observando, descobrindo e criando. Porto Alegre: Mediação, 2017.

STACCIOLI, G. Diário do acolhimento na escola da infância. Campinas: Autores Associados, 2013.

VALLE, L. D.; FREISLEBEN, J. M. A potência edu(vo)cativa das artes visuais. In: CUNHA, S. R. V. da; CARVALHO, R. S. de. Arte contemporânea e educação infantil: crianças observando, descobrindo e criando. Porto Alegre: Mediação, 2017.

Recebido em: 07 de março de 2021 .

Versão corrigida recebida em: 12 de março de 2021 .

Aceito em: 15 de março de 2021.

Publicado online em: 26 de março de 2021. 